\title{
Recruiting Post Docs to Diversity the faculty in Engineering Technology
}

\section{Dr. Keith V. Johnson, East Tennessee State University}

Dr. Keith V. Johnson is chair of the Department of Engineering Technology, Surveying and Digital Media at East Tennessee State University. He received his Ph.D. from Ohio State University and his M.S. and B.S. from North Carolina A\&T State University. He has published numerous manuscripts and have authored several successful grants. His research interest includes, but not limited to recruitment and retention of faculty and students of color in Engineering Technology. 
Recruiting Post Docs to Diversify Faculty in Engineering Technology

Abstract:

The purpose of the paper is to describe the process of recruiting and retaining faculty of color to diversify the faculty in Engineering Technology programs and to enhance an already good experience that many traditional faculty members bring to the classroom. This paper will address the process that East Tennessee State University uses to target highly qualifies faculty of color to an institution located in an area were race and culture may not be as diverse as in other areas of the country.

The problem this paper addresses is the low representation of minority faculty members in academic departments at ETSU, including Engineering Technology, Surveying and Digital Media. Faculty searches have failed to identify diverse applicant pools for a significant number of faculty positions. Because of the University's history and location it is still operating under affirmative action policies.

What has been learned is that despite national efforts to increase the number of African American Ph.D's, the traditional decentralized hiring process under the authority of academic departments is not producing the needed results. This is the case even in states with public higher education systems under court monitored 
affirmative action programs. The developers have learned that market forces, as well as competition from other universities and the private sector are real issues that impact the success of faculty recruitment efforts. Salaries are not competitive at East Tennessee State University (ETSU) for the same skills and talent within the Southern Regional Educational Board institutions, as documented in the Tennessee Higher Education Commission Peer Faculty Salary Comparison reports. What has also been learned is that the organizational climate can be less than desirable for all faculty members when disproportionate burdens of service and lack of support for research initiatives exist. The climate issues are exacerbated for minority faculty which has an impact on retention. This may require further study.

With the support of the Tennessee Board of Regents Access and Diversity Grant and resources from the ETSU Office of Equity and Diversity, School of Graduate Studies, ETSU Foundation, Department of Engineering Technology, the College of Business and the Johnson City Chamber of Commerce, campus representatives attended the $18^{\text {th }}$ Annual Compact for Faculty Diversity (Compact) and the Southeastern Association of Education Opportunity Programs (SAEOPP) McNair Scholars Conference. Personal contact information and in some cases curriculum vitas were collected from over 100 prospective candidates in October, 2011 at the Compact's Institute for Teaching and Mentoring and 36 contacts from the McNair Scholars Conference. 
Communications with prospects included an auto-response first contact letter which is generated to candidates when profile information is added to the " $\mathrm{A}$ Diverse ETSU" database portal. This database is a warehouse for storing curriculum vita data for potential faculty of color for ETSU. This letter is an invitation to stay connected with ETSU for future professional development opportunities and to become engaged with the University through the A Diverse ETSU program. The database now contains over 1,200 individuals who are at various stages of obtaining their $\mathrm{Ph}$. $\mathrm{D}$. including those who have completed and those who are $\mathrm{ABD}$ and post-doctoral fellows who are seeking employment in faculty positions. The data is accessible by designated system administrators and can be queried by academic degree, and/or related college.

Eighty-three new contacts were entered into this process the first week in November, 2011. Informal emails to prospects that most closely matched the ETSU recruitment profile were sent with information directing them to the ETSU ejobs web-site. The "Save the Date" notice was sent to recruits that invited them to a four day event that exposed them to a variety of university activities which included meeting with administrators, faculty, students, community members, attending special events and touring the city and local attractions. Many contacts and follow-up communications were made by letter and telephone regarding travel arrangements for participants. Referrals of two other prospects, who were not 
Compact participants, were received from individuals who planned to visit ETSU in 2012 .

The program was viewed as successful because of the establishment and maintenance of relationships with 20 qualified minority faculty candidates. A total of 17 , after cancellations, participated including one spouse.

Building a broad base of support from departments who have benefited from the program has been intentional. This is viewed as a critical step in sustaining the program. The project has successfully engaged and provided exposure to the Department Chairs in Appalachian Studies, Bioengineering, Biological Sciences, Chemistry, Computer Information Sciences, Engineering Technology Surveying and Digital Media, Environmental Health, Health Sciences, Health Services Administration, Human Development and Learning, Mathematics, Psychology, Public Health, Social Work, and Sociology / Anthropology.

One of the most significant accomplishments resulting from this segment of, the project is the engagement of and commitment obtained from administrators. During the course of the three-year grant period, the University President (2011 and 2012), the Provost and Vice President for Academic Affairs (2010, 2011 and 2012), the Vice President for Health Affairs / Chief Operating Officer (2010, 2011 and 2012), a member of the Tennessee Board of Regents (2010, 2011, and 2012) and a member of the Tennessee Higher Education Commission each (2010, 2011, 
and 2012) have all been participants. The Deans of the College of Clinical and Rehabilitative Health Sciences, College of Education and College of Nursing and Honors College have also been involved with the candidates.

The "A Diverse ETSU" activities included networking opportunities with the faculty of the scholar's area of academic interests. In most cases either the department chair was involved or delegated interaction to another faculty member. Staying true to the factors determined to contribute to retention, attention was given to making community connections, offering family activities, and creating career match networking opportunities for spouses attending the event with prospective candidates. Summarized evaluations from participants, faculty and administrators are included as an attachment to this report.

The plan is to develop feeder school relationships for prospective candidates graduating with terminal degrees. On April 26, 2012 the "A Diverse ETSU" project was presented at the $4^{\text {th }}$ Biennial Diversity Conference in Nashville, TN. The concurrent session "Enhancing the Faculty Search Process to Achieve Faculty Diversity" provided the opportunity to share the research and model developed with participating institutions in the conference. The session received an average rating of 1.5 on a five-point scale with 1 being Excellent and 5 being poor. Follow-up has occurred with Ernesto Villarreal, Director of Diversity Services at 
Milligan College and Tiffany Cox and Bobbie Porter at Tennessee State University.

In addition to making progress on this objective, 128 contacts have been made with McNair undergraduate scholars: 57 in 2010; 35 in 2011; and 36 in 2012. These individuals were requested to complete an interest indicator, which has been forwarded to the School of Graduate Studies. An outgrowth of "A Diverse ETSU" include plans to host a campus visit for prospective graduate students attracted through the McNair program in the fall 2012.

The "A Diverse ETSU" program is a prototype of what is possible. In the past three years the project has resulted in a database of over 1,200 Ph.Ds, Ph.D. Candidates and ABDs who have gained a familiarity with programs offered by ETSU. Likewise, 273 of these individuals have had personal face to face contact with representatives of ETSU which exemplifies the University's commitment to diversifying the faculty and supporting ethnically diverse faculty in its environment. In addition, 41 of these individuals have actually visited the campus, met with department chairs, other faculty and administrators and community members. Ninety percent were African American, five percent were Hispanic and five percent were Asian-American. They have seen first- hand what the University and the community have to offer. Of these 41 individuals, we are aware that seven have applied for available positions, four have been interviewed for faculty 
positions, and two have received employment offers. To date none of them have been hired.

Through the "A Diverse ETSU" project, a critical mass of potential faculty of color has been established. The university is committed to employing two post Docs of color annually over the next three years to further encourage tenure track employment. Currently, there is one African American in a post doc position in Engineering Technology. To date, one candidate has turned down an offer, one is currently being interviewed and one is in a post doc position and is applying for a lectureship position.

Recommendations:

Institutionalize the process, by integrating "A Diverse ETSU” into the established faculty search process which is operationally defined in the Search Process Guide PPP-35. Requests for support should be made at the time the advertising plan is submitted to the Affirmative Action Officer for approval to forward to Human Resources. This recommendation will allow departments to determine job skills and qualifications specific to the position for best matches of referrals.

It is extremely important that Deans, Department heads and other administrators of influence challenge search committees to assist in achieving the 
diversity goal as outlined in the university strategic plan regarding faculty of color. In addition, it is extremely important that ownership and accountability in in place to make sure goals are being met. Without this in place, diversity of faculty will not be realized.

Additional funding, the establishment of benchmarks, staffing, an operational link to the Office of Equity and Diversity and training for all search committee members will be required, especially chairs of the committees. 